\title{
Regimes especiais de trabalho: o aeronauta e o bancário
}

\author{
Special schemes of work: Aircrews and banking professionals
}

\author{
JOÃO VICENTE ROTHFUCHS ${ }^{\mathrm{a}}$
}

\begin{abstract}
RESUMO
O presente estudo visa à análise legal, doutrinária e jurisprudencial dos regimes de trabalho das profissões de aeronauta e bancário, visando destacar as questões que diferenciam esses trabalhadores dos demais no que diz respeito à duração do trabalho.
\end{abstract}

Palavras-chave: Direito do trabalho, Duração do trabalho. Regimes especial de trabalho. Aeronauta. Bancário.

\begin{abstract}
The present paper intends to examine the statutory, doctrinal and jurisprudential issues on labor regimes of aircrews and banking professionals, aiming to highlight issues concerning their working hours that differentiate these professionals from other workers.

Keywords: Labor law. Working hours. Special schemes of work. Aircrews. Banking professionals.
\end{abstract}

\section{INTRODUÇÃO}

Desde o surgimento do Direito Laboral, as postulações por limitação à duração do trabalho vêm sendo, juntamente com as demandas por melhores salários, um dos principais itens de reivindicação da classe trabalhadora. Isso se justifica pelos mais diversos motivos, merecendo destaque o fato de o tempo ser um dos bens mais valiosos para o ser humano e, por isso, tão valorizado quanto o retorno econômico do trabalho.

$\mathrm{Na}$ passagem da "pré-história do Direito do Trabalho"1 para o seu nascimento, com o advento da Revolução Industrial, as jornadas de trabalho eram extenuantes, chegando comumente a dezesseis horas diárias. Como resposta a tal exploração surgiram as primeiras leis trabalhistas, se destacando, como precursora, na Inglaterra a Lei de Peel de 1802, que visava a limitação de jornada para aprendizes paroquianos em moinhos a doze horas ${ }^{2}$. Na sequencia, outras leis de conteúdo similar foram surgindo na Europa, estabelecendo uma tendência de redução da carga de trabalho que evoluiu até os dias atuais e em alguns países já vem sendo revista.

No Brasil, a legislação laboral estabelece como regra geral, desde a Constituição Federal de 1988, a jornada máxima de oito horas e carga semanal de trabalho de quarenta e quatro horas, reduzindo a previsão anterior de quarenta e oito horas por semana.

Paralelamente a isso, desde antes do advento da Carta de 1988, já havia na Consolidação das Leis do Trabalho e em leis esparsas previsões específicas para determinadas categorias profissionais. Quer pela penosidade maior do trabalho, quer pela sua especificidade ou, quiçá, pela força política da respectiva classe, determinados trabalhadores possuem direito a trabalhar em regimes especiais de trabalho, com cargas diferenciadas daquelas prevista para os trabalhadores em geral.

Enquadrados nesses regimes especiais de trabalho, pode-se citar uma enormidade de classes de trabalhadores, cuja exaustão nem de longe é objeto do presente estudo. Aqui, optou-se, por limitação

a Advogado. Mestre em Direito Empresarial pela Universidade de Coimbra. Professor de Direito do Trabalho na PUCRS. <Joao.rothfuchs@pucrs.br>. 
de espaço e interesse acadêmico, em se pinçar duas dessas categorias profissionais, com estatutos jurídicos bastante distintos e realidade prática ainda mais separada, e se analisar o que o Direito do Trabalho Pátrio estabelece sobre duração de trabalho para as mesmas.

Dentre várias profissões com relevância social e econômica, as categorias escolhidas foram o aeronauta e o bancário.

\section{AERONAUTA}

\subsection{Aspectos introdutórios e conceituais}

A regulamentação da profissão de aeronauta possui legislação própria, a Lei $n^{-}$7.183/1984, que ao longo dos seus cinqüenta e sete artigos estabelece uma série de disposições de natureza trabalhista, muitas das quais referentes às particularidades da duração do trabalho e dos períodos de descanso.

Em razão dessa extensa previsão legislativa, o enfoque desta primeira parte do estudo será prioritariamente de índole legal, com a análise voltada especialmente para aquilo que a lei rege minuciosamente em respeito a esse tipo de trabalhador.

Para tal, porém, necessária se faz, preliminarmente, uma breve análise conceitual, eis que existem termos concernentes ao labor do aeronauta cuja especificidade foge ao conhecimento do operador do Direito Laboral.

Em primeiro lugar, traz-se o conceito de aeronauta, transcrito no artigo $2^{\circ}$ da referida lei, nos seguintes termos:

Art. $2^{\mathrm{O}}$ Aeronauta é o profissional habilitado pelo Ministério da Aeronáutica, que exerce atividade a bordo de aeronave civil nacional, mediante contrato de trabalho.

Parágrafo único. Considera-se também aeronauta, para os efeitos desta Lei, quem exerce atividade a bordo de aeronave estrangeira, em virtude de contrato de trabalho regido pelas leis brasileiras.

Pelo conceito legal da profissão regulamentada já se pode perceber a justificativa do regime de trabalho especial. $\mathrm{O}$ aeronauta trabalha a bordo de aeronaves (civis) e, portanto, não pode, ao término da sua jornada de oito horas, simplesmente retornar para a sua residência e descansar. Além disso, assume responsabilidades superiores àquelas do trabalhador médio, pois é personagem de destaque na segurança dos voos e dos passageiros. A atividade é, portanto, diferenciada e demanda um tratamento legal específico.
Seguindo a linha introdutória, merece reflexão o fato de existirem aeronaves de diferentes portes, o que demanda diversos níveis de dedicação e responsabilidade do profissional que nelas trabalha. Para cada tipo de aeronave, há um número mínimo de tripulantes, necessários ao seu regular funcionamento e, em especial, à sua segurança. Em determinadas circunstâncias, não basta o mínimo. Faz-se necessária uma tripulação mais numerosa, contando com "redundância" de trabalhadores para determinados postos. Em razão disso, a lei estabeleceu alguns tipos de tripulação para, posteriormente, criar regras próprias conforme o nível de envolvimento do tripulante no funcionamento global da aeronave.

Disso tratam os artigos 11, 12 e 13 da referida legislação:

Art. 10. Tripulação mínima é a determinada na forma da certificação de tipo de aeronave e a constante do seu manual de operação, homologada pelo órgão competente do Ministério da Aeronáutica, sendo permitida sua utilização em vôos: locais de instrução, de experiência, de vistoria e de traslado.

Art. 11. Tripulação simples é a constituída basicamente de uma tripulação mínima acrescida, quando for o caso, dos tripulantes necessários à realização do vôo.

Art. 12. Tripulação composta é a constituída basicamente de uma tripulação simples, acrescida de um piloto qualificado a nível de piloto em comando, um mecânico de vôo, quando o equipamento assim o exigir, e o mínimo de $25 \%$ (vinte e cinco por cento) do número de comissários.

Conforme o tipo de tripulação haverá um regime de trabalho específico, consoante restará demonstrado no decorrer do artigo.

Ainda em termos iniciais, demanda atenção o artigo 51, que trata do conceito de base do aeronauta, estabelecendo que "considera-se base do aeronauta a localidade onde o mesmo está obrigado a prestar serviços e na qual deverá ter domicílio". O fato de estar ou não na sua base gera consequências em termos de jornada, conforme será tratado em seguida.

\subsection{Escala de serviço}

Outra peculiaridade da profissão, esta já diretamente vinculada à duração do trabalho, são as escalas de serviço. $\mathrm{O}$ aeronauta deve trabalhar submetido a escalas, já que tem de estar disponível ao seu empregador para atender as necessidades da atividade, que muitas vezes demandam um longo período ausente de sua residência e, como consequência, do regular convívio familiar. Como contrapartida, possui direito a limitações 
nessas escalas, a tomar ciência das mesmas com razoável antecedência e a receber folgas e repousos regulamentares. Nesse sentido, estabelece o artigo 17:

Art. 17. A determinação para a prestação de serviço dos aeronautas, respeitados os períodos de folgas e repousos regulamentares, será feita:

a) por intermédio de escala especial ou de convocação, para realização de cursos, exames relacionados com o adestramento e verificação de proficiência técnica;

b) por intermédio de escala, no mínimo semanal, divulgada com antecedência mínima de 2 (dois) dias para a primeira semana de cada mês e 7 (sete) dias para as semanas subseqüentes, para os vôos de horário, serviços de reserva, sobreaviso e folga; $\mathrm{e}$

c) mediante convocação, por necessidade de serviço.

\subsection{Jornada de trabalho}

O regramento acerca da jornada de trabalho do aeronauta demonstra-se bastante complexo, considerando uma série de variáveis como o tipo de aeronave, qual o contingente da tripulação e o fato de o empregado estar ou não iniciando o trabalho em sua base. Existem, assim, diferentes hipóteses de tempo de trabalho, conforme se observa dos artigos a seguir transcritos:

Art. 20. Jornada é a duração do trabalho do aeronauta, contada entre a hora da apresentação no local de trabalho e a hora em que o mesmo é encerrado.

$\S 1^{\circ}$ A jornada na base domiciliar será contada a partir da hora de apresentação do aeronauta no local de trabalho.

$\S 2^{\underline{O}}$ Fora da base domiciliar, a jornada será contada a partir da hora de apresentação do aeronauta no local estabelecido pelo empregador.

$\S 3^{\circ}$ Nas hipóteses previstas nos parágrafos anteriores, a apresentação no aeroporto não deverá ser inferior a 30 (trinta) minutos da hora prevista para o início do vôo.

$\S 4^{\circ}$ A jornada será considerada encerrada 30 (trinta) minutos após a parada final dos motores.

No caput do artigo 20 é estabelecida a forma de cômputo da jornada de trabalho do aeronauta, determinando, como regra geral, qual o tempo em que o aeronauta está à disposição do seu empregador - da apresentação no local de trabalho ao encerramento do mesmo. Os parágrafos, contudo, tratam de previsões específicas para o labor na base e fora da base. Estabelecem, outrossim, presunção mínima de tempo à disposição, que pode ser afastada por prova que estabeleça períodos de labor que excedam aos trinta minutos anteriores à hora prevista para o início do voo e os trinta minutos posteriores à parada final dos motores ${ }^{3}$.

O artigo 21, por sua vez, passa a estabelecer as jornadas de trabalho conforme o tipo de tripulação - se mínima, composta ou de revezamento. Prevê jornadas que vão aumentando consoante também cresce o número de tripulantes na aeronave; ou seja, para tripulação mínima ou simples a jornada será de onze horas; para tripulação composta, de catorze horas e para tripulação de revezamento, de vinte horas. Tais diferenciações se justificam pela especificidade da atividade, que demanda uma responsabilidade que crescerá em proporção inversa ao número de tripulantes a bordo. As extensas jornadas, por sua vez, são fruto das longas distâncias percorridas pelos aviões intercontinentais e por isso são desenvolvidas em aeronaves com tripulações excedentes à mínima.

Art.21. A duração da jornada de trabalho do aeronauta será de:

a) 11 (onze) horas, se integrante de uma tripulação mínima ou simples;

b) 14 (quatorze) horas, se integrante de uma tripulação composta; e

c) 20 (vinte) horas, se integrante de uma tripulação de revezamento.

$\S 1^{o}$ Nos vôos de empresa de táxi aéreo, de serviços especializados, de transporte aéreo regional ou em vôos internacionais regionais de empresas de transporte aéreo regular realizados por tripulação simples, se houver interrupção programada da viagem por mais 4 (quatro) horas consecutivas, e for proporcionado pelo empregador acomodações adequadas para repouso dos tripulantes, a jornada terá a duração acrescida da metade do tempo de interrupção, mantendo-se inalterado os limites prescritos na alínea "a" do art. 29 desta Lei.

$\S 2^{\circ}$ Nas operações com helicópteros a jornada poderá ter a duração acrescida de até 1 (uma) hora para atender exclusivamente a trabalhos de manutenção.

Existe, ainda, a possibilidade de ampliação desses limites, conforme o comandante - autoridade máxima em voo - observa a ocorrência de alguma das hipóteses legalmente prevista no artigo 22:

Art.22. Os limites da jornada de trabalho poderão ser ampliados de 60 (sessenta) minutos, a critério exclusivo do comandante da aeronave e nos seguintes casos:

a) inexistência, em local de escala regular, de acomodações apropriadas para o repouso da tripulação e dos passageiros; 
b) espera demasiadamente longa, em local de espera regular intermediária, ocasionada por condições meteorológicas desfavoráveis ou por trabalho de manutenção; e

c) por imperiosa necessidade.

$\S 1^{\text {o }}$ Qualquer ampliação dos limites das horas de trabalho deverá ser comunicada pelo comandante ao empregador, 24 (vinte e quatro) horas após a viagem, o qual, no prazo de 15 (quinze) dias, a submeterá à apreciação do Ministério da Aeronáutica.

$\S 2^{\mathrm{O}}$ Para as tripulações simples, o trabalho noturno não excederá de $10(\mathrm{dez})$ horas.

§3ำ Para as tripulações simples nos horários mistos, assim entendidos os que abrangem períodos diurnos e noturnos, a hora de trabalho noturno será computada como de 52 (cinqüenta e dois) minutos e 30 (trinta) segundos.

Já o artigo 23, em contrapartida à elastecida jornada regrada nos dispositivos anteriores, prevê limite mensal de carga de trabalho substancialmente inferior ao constitucional, garantindo que embora o trabalhador possa ter uma carga semanal de sessenta horas, o número de horas de trabalho mensal não será superior a cento e setenta e seis. Além disso, tais limites não dizem respeito apenas à jornada efetiva, mas também às horas de reserva e de sobreaviso, que serão tratadas em tópico próprio, ao tempo do deslocamento, como tripulante extra, para assumir voo ou retornar à base após o voo e aos tempos de adestramento em simulador. Ou seja, a limitação mensal de trabalho considera todas as hipóteses em que o aeronauta está à disposição do seu empregador, efetivamente trabalhando ou não.

Se por um lado o legislador compreende que é impossível limitar a jornada de trabalho da mesma forma que o trabalhador normal, pois o tempo de voo necessário para o deslocamento de um local a outro em muitas vezes supera em muito às oito horas, por outro estabelece limites mensais muito mais favoráveis a esses trabalhadores, como forma de compensação.

Art.23. A duração do trabalho do aeronauta, computados os tempos de vôo, de serviço em terra durante a viagem, de reserva e de 1/3 (um terço) do sobreaviso, assim como o tempo do deslocamento, como tripulante extra, para assumir vôo ou retornar à base após o vôo e os tempos de adestramento em simulador, não excederá a 60 (sessenta) horas semanais e 176 (cento e setenta e seis) horas mensais.

$\S 1^{\circ}$ O limite semanal estabelecido neste artigo não se aplica ao aeronauta que estiver sob o regime estabelecido no art. 24 desta Lei.

$\S 2^{\mathrm{o}} \mathrm{O}$ tempo gasto no transporte terrestre entre o local de repouso ou da apresentação, e vice-versa, ainda que em condução fornecida pela empresa, na base do aeronauta ou fora dela, não será computado como de trabalho para fins desta Lei.

Não se pode confundir jornada de trabalho com tempo de voo. A lei trata paralelamente dos dois conceitos e estabelece limites temporais também para o último. A abrangência da jornada é mais ampla por englobar períodos em que o trabalhador não está efetivamente voando. Também merece atenção o fato de que dentro do período de jornada, o aeronauta tem o número pousos limitado, eis que tal procedimento, juntamente com a decolagem, é o que demanda maior atenção e, como consequência, desgaste mental e físico.

O artigo 28 estabelece o que é tempo de voo e o artigo 29 prevê os limites, consoante se observa:

Art. 28 Denomina-se "hora de vôo" ou "tempo de vôo" o período compreendido entre o início do deslocamento, quando se tratar de aeronave de asa fixa, ou entre a "partida" dos motores, quando se tratar de aeronave de asa rotativa, em ambos os casos para fins de decolagem até o momento em que respectivamente, se imobiliza ou se efetua o "corte" dos motores, ao término do vôo (calço-a-calço).

Art. 29 Os limites de vôo e pousos permitidos para uma jornada serão os seguintes:

a) 9 (nove) horas e 30 (trinta) minutos de vôo e 5 (cinco) pousos, na hipótese de integrante de tripulação mínima ou simples;

b) 12 (doze) horas de vôo e 6 (seis) pousos, na hipótese de integrante de tripulação composta;

c) 15 (quinze) horas de vôo e 4 (quatro) pousos, na hipótese de integrante de tripulação de revezamento; e

d) 8 (oito) horas sem limite de pousos, na hipótese de integrante de tripulação de helicópteros.

$\S 1^{\circ}$ O número de pousos na hipótese da alínea "a" deste artigo, poderá ser estendido a 6 (seis), a critério do empregador; neste caso o repouso que precede a jornada deverá ser aumentado de 1 (uma) hora.

$\S 2^{\circ} \quad$ Em caso de desvio para alternativa, é permitido o acréscimo de mais 1 (um) pouso aos limites estabelecidos nas alíneas "a", "b" e "c" deste artigo.

$\S 3^{\circ}$ As empresas de transporte aéreo regional que operam com aeronaves convencionais e turbo hélice poderão acrescentar mais 4 (quatro) pousos, aos limites estabelecidos neste artigo.

$\S 4^{\circ}$ Os limites de pousos estabelecidos nas alíneas "a", "b" e "c" deste artigo, não serão aplicados às empresas de táxi aéreo e de serviços especializados. 
$\S 5^{\circ}$ O Ministério da Aeronáutica, tendo em vista as peculiaridades dos diferentes tipos de operação, poderá reduzir os limites estabelecidos na alínea "d" deste artigo.

O tempo de voo também possui limitações, em periodicidades mensal, trimestral e anual, variando conforme o tipo de aeronave ${ }^{4}$.

\subsection{Sobreaviso e reserva}

Além da duração do trabalho efetivo, o aeronauta possui, ainda, reguladas pela legislação especial, as horas de reserva e de sobreaviso. Embora em ambas as situações o trabalhador esteja "à disposição do empregador", sem realizar trabalho efetivo, o sobreaviso se diferencia da reserva basicamente pelo local em que esse tempo à disposição é ofertado pelo aeronauta. No caso do sobreaviso, o aeronauta permanece "em local de sua escolha" enquanto na reserva, "em local de trabalho".

Art. 25. Sobreaviso é o período de tempo não excedente a 12 (doze) horas, em que o aeronauta permanece em local de sua escolha, à disposição do empregador, devendo apresentar-se no aeroporto ou outro local determinado, até 90 (noventa) minutos após receber comunicação para o início de nova tarefa.

$\S 1$ o O número de sobreavisos que o aeronauta poderá concorrer não deverá exceder a 2 (dois) semanais ou 8 (oito) mensais.

$\S 2^{\mathrm{o}}$ O número de sobreavisos estabelecidos no parágrafo anterior não se aplica aos aeronautas de empresas de táxi aéreo ou serviço especializado.

Art.26. Reserva é o período de tempo em que o aeronauta permanece, por determinação do empregador, em local de trabalho à sua disposição.

$\S 1^{\circ}$ O período de reserva para aeronautas de empresas de transporte aéreo regular não excederá de 6 (seis) horas.

$\S 2^{\circ}$ O período de reserva para aeronautas de empresas de táxi aéreo ou de serviços especializados não excederá de $10(\mathrm{dez})$ horas.

$\S 3^{\circ}$ Prevista a reserva, por prazo superior a 3 (três) horas, o empregador deverá assegurar ao aeronauta acomodações adequadas para o seu descanso.

\subsection{Repouso e folga periódica}

Diretamente ligadas ao tempo de trabalho, estão as previsões referentes ao repouso e à folga periódica. Os artigos 32 a 36 tratam dos repousos e 37 a 39 da folga periódica, merecendo destaque os conceitos dos institutos:
Art.32. Repouso é o espaço de tempo ininterrupto após uma jornada, em que o tripulante fica desobrigado da prestação de qualquer serviço.

Art. 37. Folga é o período de tempo não inferior a 24 (vinte e quatro) horas consecutivas em que o aeronauta, em sua base contratual, sem prejuízo de remuneração, está desobrigado de qualquer atividade relacionada com seu trabalho.

Para ambas as hipóteses, há extenso regramento prevendo períodos de necessário descanso após o desgastante trabalho, característica da profissão.

\section{BANCÁRIO}

\subsection{Aspectos introdutórios e conceituais}

Em situação diametralmente oposta à dos aeronautas, no que diz respeito à complexidade das previsões legais sobre a jornada, o regime de trabalho do bancário possui uma construção doutrináriajurisprudencial consideravelmente mais relevante e, por isso, terá maior destaque do que texto da lei, exaustivamente trabalhado no capítulo anterior.

Apesar disso, aspectos conceituais prévios também serão necessários para se compreender a quem é direcionado esse estudo.

Iniciando pela análise da previsão legal, essencial a citação do caput do artigo 224 da Consolidação das Leis do Trabalho:

Art.224, A duração normal do trabalho dos empregados em bancos, casas bancárias e Caixa Econômica Federal será de 6 (seis) horas continuas nos dias úteis, com exceção dos sábados, perfazendo um total de 30 (trinta) horas de trabalho por semana.

Tal previsão, inaugurando a Seção I do Capitulo I do Título III da CLT, que rege sobre normas especiais de tutela do trabalho, deixa clara a intenção legislativa: proteger, de forma diferenciada, os trabalhadores bancários, assim considerados aqueles empregados em "bancos, casas bancárias e na Caixa Econômica Federal", limitando a sua jornada de trabalho ordinária para seis horas. O texto consolidado estabelece, ainda, em seu artigo 226, que mesmo os "empregados de portaria e de limpeza, tais como porteiros, telefonistas de mesa, contínuos e serventes", desde que, empregados em bancos e casas bancárias, terão direito a jornada reduzida.

Existem, ainda, outras situações em que se sustentou analogia com o trabalho bancário para fim de se estender a jornada reduzida. Após debates interpretativos acerca da aplicabilidade ou não dessa 
carga inferior de trabalho a categorias que entendiam, por isonomia, que deveriam fazer jus ao mesmo tratamento legal, coube à jurisprudência estabelecer limites.

Assim, o Tribunal Superior do Trabalho, por meio de Súmulas, consolidou posicionamento acerca de quais as situações em que se aplica e quais que não se aplica o regime diferenciado, destacando-se as seguintes:

SUM-55 FINANCEIRAS (mantida) - Res. 121/2003, DJ 19, 20 e 21.11.2003 As empresas de crédito, financiamento ou investimento, também denominadas financeiras, equiparam-se aos estabelecimentos bancários para os efeitos do art. 224 da CLT.

SUM-117 BANCÁRIO. CATEGORIA DIFERENCIADA (mantida) - Res. 121/2003, DJ 19, 20 e 21.11.2003. Não se beneficiam do regime legal relativo aos bancários os empregados de estabelecimento de crédito pertencentes a categorias profissionais diferenciadas.

SUM-119 JORNADA DE TRABALHO (mantida) - Res. 121/2003, DJ 19, 20 e 21.11.2003 Os empregados de empresas distribuidoras e corretoras de títulos e valores mobiliários não têm direito à jornada especial dos bancários.

SUM-239 BANCÁRIO. EMPREGADO DE EMPRESA DE PROCESSAMENTO DE DADOS (incorporadas as Orientações Jurisprudenciais $\mathrm{n}^{\mathrm{O} s}$ 64 e 126 da SBDI-1) - Res. 129/2005, DJ 20, 22 e 25.04.2005. É bancário o empregado de empresa de processamento de dados que presta serviço a banco integrante do mesmo grupo econômico, exceto quando a empresa de processamento de dados presta serviços a banco e a empresas não bancárias do mesmo grupo econômico ou a terceiros. (primeira parte - ex-Súmula no 239 - Res. 15/1985, DJ 09.12.1985; segunda parte - ex-OJs $n^{\text {os }} 64$ e 126 da SBDI-1 - inseridas, respectivamente, em 13.09.1994 e 20.04.1998)

SUM-257 VIGILANTE (mantida) - Res. 121/2003, DJ 19, 20 e 21.11.2003. O vigilante, contratado diretamente por banco ou por intermédio de empresas especializadas, não é bancário.

A proteção especial se justificou, à época da sua criação, em razão da excessiva penosidade de tal tipo de trabalho. Segadas Vianna reconhece que "a complexidade de operações, as responsabilidades no manuseio de grandes somas e até mesmo a posição de trabalho curvado sobre a mesma provocam, ao fim de curto tempo, o extenuamento do empregado bancário". 5,6

Apesar de a regra geral ser de jornada reduzida, de seis horas, existe na legislação, ainda, previsão excepcional para jornada de oito horas. Ambas as hipóteses serão tratadas a seguir.

\subsection{Jornada de seis horas}

Conforme narrado, supra, a jornada regular do bancário é de seis horas, consoante previsão do caput do artigo 224 da CLT, perfazendo uma carga total semanal de trinta horas. O parágrafo primeiro prevê que essas seis horas serão cumpridas entre as 7 e as 22 horas e que será concedido ao bancário um intervalo de quinze minutos.

$\mathrm{O}$ primeiro aspecto que merece destaque é a previsão de carga semanal de trinta horas. Se os dias úteis semanais são de segunda a sábado, seis horas por dia representariam trinta e seis horas semanais, ao invés das trinta. A lei, porém, é clara: serão trabalhadas seis horas nos dias úteis, com exceção do sábado.

A consequência desta previsão é o enquadramento do sábado. Seria dia útil não trabalhado ou mais um dia de repouso remunerado? Essa discussão levará a consequências remuneratórias importantes, pois conforme a conclusão, teremos mais um dia de repouso remunerado e um divisor diferente para o cômputo do salário hora e a correspondente quantificação das horas extras.

Uma interpretação literal do contido no artigo leva à conclusão de que o sábado é expressamente tratado como dia útil, pois a lei prevê que o trabalho será "nos dias úteis, com exceção do sábado". Dada essa interpretação, conclui-se que sábado é dia útil, pois a lei assim afirma, em que não há trabalho e, portanto, não pode ser tratado como se configurasse mais um dia de repouso semanal remunerado. Tal interpretação é respaldada pelo Tribunal Superior do Trabalho, através da Súmula 113:

SUM-113 - BANCÁRIO. SÁBADO. DIA ÚTIL (mantida) - Res. 121/2003, DJ 19, 20 e 21.11.2003. O sábado do bancário é dia útil não trabalhado, não dia de repouso remunerado. Não cabe a repercussão do pagamento de horas extras habituais em sua remuneração.

Para o cômputo do salário-hora, o TST parte da mesma premissa, estabelecendo com regra geral a consideração do sábado como dia útil não trabalhado, salvo se houver ajuste individual ou coletivo em sentido contrário. Assim, conforme se esteja tratando de jornada de seis ou oito horas, ter-se-á os divisores 180 ou 150 ; ou 220 ou 200 : 
SUM-124 BANCÁRIO. SALÁRIO-HORA. DIVISOR (redação alterada na sessão do Tribunal Pleno realizada em 14.09.2012) - Res. 185/2012 DEJT divulgado em 25, 26 e 27.09.2012

I - O divisor aplicável para o cálculo das horas extras do bancário, se houver ajuste individual expresso ou coletivo no sentido de considerar o sábado como dia de descanso remunerado, será:

a) 150, para os empregados submetidos à jornada de seis horas, prevista no caput do art. 224 da CLT;

b) 200, para os empregados submetidos à jornada de oito horas, nos termos do $\S 2^{\underline{Q}}$ do art. 224 da CLT.

II - Nas demais hipóteses, aplicar-se-á o divisor:

a) 180 , para os empregados submetidos à jornada de seis horas prevista no caput do art. 224 da CLT;

b) 220, para os empregados submetidos à jornada de oito horas, nos termos do $\S 2^{\mathrm{o}}$ do art. 224 da CLT.

Também conforme entendimento consagrado pela jurisprudência do TST, o intervalo de quinze minutos previsto na disposição legal não é computável na jornada de trabalho:

OJ 178 SDI-1 BANCÁRIO. INTERVALO DE 15 MINUTOS. NÃO COMPUTÁVEL NA JORNADA DE TRABALHO (inserido dispositivo) - DJ 20.04.2005. Não se computa, na jornada do bancário sujeito a seis horas diárias de trabalho, o intervalo de quinze minutos para lanche ou descanso.

\subsection{Jornada de oito horas}

Para além da previsão geral de jornada de seis horas para o empregado bancário, a CLT excepciona a possibilidade de jornada de oito horas para "funções de direção, gerência, fiscalização, chefia e equivalentes, ou que desempenhem outros cargos de confiança", desde que com percepção de gratificação de função de no mínimo um terço. Tal regra está prevista no parágrafo segundo do artigo 224 da CLT:

Art. 224. (...) $\S 2^{\mathrm{O}}$ As disposições deste artigo não se aplicam aos que exercem funções de direção, gerência, fiscalização, chefia e equivalentes, ou que desempenhem outros cargos de confiança, desde que o valor da gratificação não seja inferior a $1 / 3$ (um terço) do salário do cargo efetivo.
A referida disposição traz ao universo Jus-laboral o chamado "cargo de confiança bancário", que é diferente do cargo de confiança "geral" previsto no artigo 62 da CLT $^{7}$.

Russomano $^{8}$ estabelece diferentes níveis de fidúcia existentes na legislação pátria, enquadrando a hipótese prevista no artigo 224, $\S 2^{\circ}$, da CLT, como de "confiança específica", enquanto aquela do artigo 62, II, seria de "confiança excepcional". Alice Monteiro de Barros", seguindo a mesma lógica, sustenta que o cargo de confiança excepcional (art.62) é apenas aquele capaz de "colocar em jogo a própria existência da empresa, seus interesses fundamentais, sua segurança e a ordem essencial do desenvolvimento da sua atividade". Já o de "confiança especial" (art.224), seria aquele que "pressupõe atividades de coordenação, supervisão ou fiscalização, não exigindo a lei amplos poderes de gestão".

Em realidade, os textos legais são bastante semelhantes, prevendo, todavia, consequências distintas. Enquanto na regra geral do artigo 62 a caracterização como gerente serve para excluir a possibilidade de controle de horário, na previsão específica do bancário funciona apenas para afastar do regime de trabalho especial de seis horas diárias, passando o trabalhador a laborar por oito horas. A consequência, aqui, é mais branda, pois o trabalhador ainda tem a jornada limitada e, como consequência, direito à percepção de horas extras.

Seguindo o consagrado doutrinariamente, o TST diferencia os níveis de fidúcia do gerente (art. 62) para o gerente bancário (art.224), de maneira simples e objetiva. Estabelece a Súmula 287:

SUM-287 JORNADA DE TRABALHO. GERENTE BANCÁRIO (nova redação) - Res. $121 / 2003$, DJ 19, 20 e 21.11.2003. A jornada de trabalho do empregado de banco gerente de agência é regida pelo art. 224, §2o , da CLT. Quanto ao gerente-geral de agência bancária, presume-se o exercício de encargo de gestão, aplicando-se-lhe o art. 62 da CLT.

Ou seja, segundo o Tribunal Superior do Trabalho, apenas o gerente geral da agência estaria enquadrado no artigo 62, II, da CLT, estando dispensado de controle de horário. Os demais gerentes apenas não têm direito a jornada de seis horas, mas estão submetidos à jornada de oito horas devidamente controlada e fazem jus a horas extraordinárias.

Ainda sobre a matéria, esclarece a Súmula 102 do TST diversas hipóteses pontuais: 
SUM-102 BANCÁRIO. CARGO DE CONFIANÇA (mantida) - Res. 174/2011, DEJT divulgado em 27, 30 e 31.05.2011.

I - A configuração, ou não, do exercício da função de confiança a que se refere o art. 224, $\S 2^{\circ}$, da CLT, dependente da prova das reais atribuições do empregado, é insuscetível de exame mediante recurso de revista ou de embargos. (ex-Súmula no 204 - alterada pela Res. 121/2003, DJ 21.11. 2003)

II - O bancário que exerce a função a que se refere o $\S 2^{\circ}$ do art.224 da CLT e recebe gratificação não inferior a um terço de seu salário já tem remuneradas as duas horas extraordinárias excedentes de seis. (ex-Súmula no 166 - RA 102/1982, DJ 11.10.1982 e DJ 15.10.1982)

III - Ao bancário exercente de cargo de confiança previsto no artigo $224, \S 2^{\circ}$, da CLT são devidas as $7^{\underline{a}}$ e $8^{\underline{a}}$ horas, como extras, no período em que se verificar o pagamento a menor da gratificação de 1/3. (ex-OJ no 288 da SBDI-1 - DJ 11.08.2003)

IV - O bancário sujeito à regra do art. $224, \S 2^{2}$, da CLT cumpre jornada de trabalho de 8 (oito) horas, sendo extraordinárias as trabalhadas além da oitava. (ex-Súmula no 232- RA 14/1985, DJ 19.09.1985)

$\mathrm{V}$ - O advogado empregado de banco, pelo simples exercício da advocacia, não exerce cargo de confiança, não se enquadrando, portanto, na hipótese do $\S 2^{\underline{o}}$ do art. 224 da CLT. (ex-OJ n ${ }^{\circ} 222$ da SBDI-1 - inserida em 20.06.2001)

VI - O caixa bancário, ainda que caixa executivo, não exerce cargo de confiança. Se perceber gratificação igual ou superior a um terço do salário do posto efetivo, essa remunera apenas a maior responsabilidade do cargo e não as duas horas extraordinárias além da sexta. (ex-Súmula no 102 - RA 66/1980, DJ 18.06.1980 e republicada DJ 14.07.1980)

VII - O bancário exercente de função de confiança, que percebe a gratificação não inferior ao terço legal, ainda que norma coletiva contemple percentual superior, não tem direito às sétima $\mathrm{e}$ oitava horas como extras, mas tão somente às diferenças de gratificação de função, se postuladas. (ex-OJ nº 15 da SBDI-1 - inserida em 14.03.1994)

Da extensa previsão sumulada, múltiplos aspectos são relevantes, merecendo destaque o fato de que a configuração da função de confiança depende da análise fática das atividades desenvolvidas, aplicandose o princípio da primazia da realidade em situações nas quais, de fato, não há a necessária fidúcia para se caracterizar o cargo como de confiança.

Ou seja, o bancário deverá exercer efetivamente a função que demanda aquilo que Russomano ${ }^{10}$ deno- mina de "fidúcia especial" e, ainda, cumulativamente, perceber a gratificação de pelo menos um terço do valor do salário efetivo. Nessas hipóteses, não terá direito ao regime especial de seis horas, mas estará submetido a jornada de oito horas e fará jus a horas extras que excederem a essas oito.

Se for observado que, de fato, determinado trabalhador bancário enquadrado como gerente e submetido a jornada de oito horas não realiza, no contrato-realidade, função de confiança, a consequência será que a sétima e a oitava hora serão devidas como horas extras, não sendo compensável no pagamento destas a gratificação de função, consoante Súmula 109 do TST:

SUM-109 GRATIFICAÇÃO DE FUNÇÃO (mantida) - Res. 121/2003, DJ 19, 20 e 21.11.2003. O bancário não enquadrado no $\S 2^{\circ}$ do art. 224 da CLT, que receba gratificação de função, não pode ter o salário relativo a horas extraordinárias compensado com o valor daquela vantagem.

\section{CONCLUSÃO}

O breve apanhado supra, sobre as profissões de bancário e aeronauta, serve para demonstrar o quão amplo é o espaço para a discussão dos regimes de trabalho dessas duas profissões, que são apenas uma amostragem dos diversos regimes especiais de trabalho previstos na legislação brasileira.

A análise do aeronauta foi realizada, propositadamente, com ênfase especial na legislação, já que há inúmeras regras próprias que precisam ser visitadas para que se tenha uma visão abrangente dessa forma efetivamente diferenciada de limitação ao trabalho. O bancário, por sua vez, demandou um estudo muito mais voltado à jurisprudência, com ênfase naquilo que é pacífico no entendimento do TST.

Para ambas as profissões, caberia muito aprofundamento, quer doutrinário, quer em uma pesquisa jurisprudencial mais ampla, tratando de aspectos polêmicos. Face à limitação de espaço deste artigo, optou-se, porém, por uma análise mais conservadora, tratando daquilo que é pouco discutível, com a intenção levar ao leitor o básico necessário à compreensão do trabalho nas duas profissões.

Fica em aberto o convite para o aprofundamento.

\section{REFERÊNCIAS}

BARROS, Alice Monteiro de. Curso de Direito do Trabalho. São Paulo: LTr, 2010.

BRASIL. Decreto-Lei no 5452, de $1^{\text {o }}$ de maio de 1943, (Consolidação das Leis do Trabalho). Disponível em: <http://www. 
planalto.gov.br/ccivil/Decreto-Lei/Del5452compilado.htm>. Acesso em: 23 dez. 2013.

BRASIL. Lei $n^{-}$7.183, de 5 de abril de 1984. Disponível em: $<$ http://www.planalto.gov.br/ccivil_03/leis/L7183.htm>. Acesso em: 5 dez. 2013.

CATHARINO, José Martins. Compendio de Direito do Trabalho. 2. ed. São Paulo: Saraiva, 1981.
MARTINS, Sérgio Pinto. Direito do Trabalho. 28. ed. São Paulo: Atlas, 2012.

RUSSOMANO, Mozart Victor. Curso de Direito do Trabalho. 6. ed. Curitiba: Juruá, 1997.

VIANNA, Segadas; SÜSSEKIND, Arnaldo et al. Instituições de Direito do Trabalho. 22. ed. São Paulo: LTR, 2005.

\section{NOTAS}

1 CATHARINO, José Martins. Compêndio de Direito do Trabalho. 2. ed. São Paulo: Saraiva, 1981. p. 3.

2 MARTINS, Sérgio Pinto. Direito do Trabalho. 28. ed. São Paulo: Atlas, 2012. p. 7.

3 EMENTA: AERONAUTAS. JORNADA DE TRABALHO. HORAS EXTRAS. TEMPO A DISPOSIÇÃO ANTES E APÓS O VOO. Por imposição legal, os aeronautas devem estar no local de trabalho, no mínimo, meia hora antes do voo, sendo que a jornada é tida como encerrada após transcorrido esse mesmo tempo, contados da parada final dos motores da aeronave ( $\S \S 3^{\circ}$ e e $4^{\circ}$ do art. 20 da Lei $\left.n^{\mathrm{o}} 7.813 / 84\right)$. Fora destes limites, não se pode entender que o salário normal remunera todo o tempo que o empregado fica a disposição. Na espécie, a própria reclamada admite que determinava o comparecimento dos comissários de bordo em período que excede este limite, o qual deve ser remunerado como trabalho em horário extraordinário. (TRT 4aㅡ Região, Proc. 0000705-98.2011.5.04.0026 RO, Relator MANUEL CID JARDON, data 19/02/2014, Disponível em: <www.trt4.jus.br>. Acesso em: 23 fev. 2014).

4 Art. 30. Os limites de tempo de vôo do tripulante não poderão exceder em cada mês, trimestre ou ano, respectivamente:

em aviões convencionais: $100-270-1000$ horas;

em aviões: $100-255$ - 935 horas; em aviões a jato: $85-230-850$ horas; e

em helicópteros: $90-260-960$ horas.

5 VIANNA, Segadas; SÜSSEKIND, Arnaldo, et al. Instituições de Direito do Trabalho, p. 1034

6 Não caberia no objeto do presente estudo a análise da contextualização desta afirmativa aos dias atuais, em face dos novos desafios do mercado de trabalho, em que, s.m.j., a profissão de bancário se aproximou muito, em nível de penosidade, em especial mental, da grande maioria das profissões intelectuais. Apenas a título reflexivo, será que tal diferenciação, prevendo jornada de seis horas ao invés de oito apenas para essa atividade profissional ainda se justifica e possui respaldo fáticojurídico no atual mercado de trabalho?

7 Art. 62. Não são abrangidos pelo regime previsto neste capítulo: (...) II - os gerentes, assim considerados os exercentes de cargos de gestão, aos quais se equiparam, para efeito do disposto neste artigo, os diretores e chefes de departamento ou filial.

Parágrafo único. O regime previsto neste capítulo será aplicável aos empregados mencionados no inciso II deste artigo, quando o salário do cargo de confiança, compreendendo a gratificação de função, se houver, for inferior ao valor do respectivo salário efetivo acrescido de 40\% (quarenta por cento).

8 RUSSOMANO, Mozart Victor. Curso de Direito do Trabalho, p. 138

9 BARROS, Alice Monteiro de. Curso de Direito do Trabalho, p. 703.

${ }^{10}$ Op. loc. cit. 